\title{
Thermal Analysis of Simulated Pantex Pit Storage
}

S. M. Aceves

B. T. Kornblum

October 1996

This is an informal report intended primarily for internal or limited external distribution. The opinions and conclusions stated are those of the author and may or may not be those of the Laboratory.

Work performed under the auspices of the U.S. Department of Energy by the Lawrence Livermore National Laboratory under Contract W-7405-Eng-48. 


\section{DISCLAIMER}

This document was prepared as an account of work sponsored by an agency of the United States Government. Neither the United States Government nor the University of California nor any of their employees, makes any warranty, express or implied, or assumes any legal liability or responsibility for the accuracy, completeness, or usefulness of any information, apparatus, product, or process disclosed, or represents that its use would not infringe privately owned rights. Reference herein to any specific commercial product, process, or service by trade name, trademark, manufacturer, or otherwise, does not necessarily constitute or imply its endorsement, recommendation, or favoring by the United States Government or the University of California. The views and opinions of authors expressed herein do not necessarily state or reflect those of the United States Government or the University of California, and shall not be used for advertising or product endorsement purposes.

This report has been reproduced directly from the best available copy.

Available to DOE and DOE contractors from the Office of Scientific and Technical Information P.O. Box 62, Oak Ridge, TN 37831

Prices available from (615) 576-8401, FTS 626-8401

Available to the public from the National Technical Information Service

U.S. Department of Commerce 5285 Port Royal Rd. Springfield, VA 22161 


\title{
Thermal Analysis of Simulated Pantex Pit Storage
}

\author{
by \\ Salvador M. Aceves and Barbara T. Kornblum
}

\begin{abstract}
This report investigates potential pit storage configurations that could be used at the Mason and Hanger Pantex Plant. The study utilizes data from a thermal test series performed at Lawrence Livermore National Laboratory (LLNL) that simulated these storage configurations. The heat output values used in the LLNL test series do not represent actual pits but are rounded numbers that were chosen for convenience to allow parameter excursions.
\end{abstract}

Specifically in this project, we are modeling the heat transfer and air flow around cylindrical storage containers in Pantex magazines in order to predict container temperatures. This difficult problem in thermal-fluid mechanics involves transient, threedimensional (3-D) natural convection and thermal radiation around interacting containers with various heat generation rates. Our approach is to link together two computational methods in order to synthesize a modeling procedure for a large array of pit storage containers. The approach employs a finite element analysis of a few containers, followed by a lumped-parameter model of an array of containers.

The modeling procedure we developed was applied in the simulation of a recent experiment where temperatures of pit storage containers were monitored in a steady-state, controlled environment. Our calculated pit container temperatures are comparable with data from that experiment. We found it absolutely necessary to include thermal radiation between containers in order to predict temperatures accurately, although the assumption of black-body radiation appears to be sufficient. When radiation is neglected the calculated temperatures are 4 to $6{ }^{\circ} \mathrm{C}$ higher than temperature data from the experiment. We also investigated our model's sensitivity to variations in the natural convection heat transfer coefficient and found that with a 50\% drop in the coefficient, calculated temperatures are approximately $1{ }^{\circ} \mathrm{C}$ higher. Finally, with a modified lumped-parameter model, we demonstrate how an entire Pantex magazine can be simulated.

\section{Introduction}

Pantex pit storage magazines have been analyzed in the past, experimentally as well as computationally $[1,2,3]$. The problem is of importance because pits generate heat, and they may therefore overheat if they are not cooled properly. Pits are stored and packaged for both structural and fire safety protection carefully inside cylindrical containers. The packaging also thermally insulates the pits and makes the problem of cooling more difficult. Currently, pit storage magazines are cooled by natural convection. A draft is created by the heat generated inside the magazine which results in air circulation through intake vents, and out through a ventilation stack. A schematic of the magazine and the container arrangement inside the magazine is shown in Figure 1. Table 1 lists approximate values for some of the most important magazine parameters.

Table 1. Magazine and storage container parameters used in this analysis, taken from $[1,2,3]$. 


\begin{tabular}{|l|c|}
\hline Magazine height, $\mathrm{m}$ & 2.8 \\
\hline Magazine length, $\mathrm{m}$ & 12.2 \\
\hline Magazine width, $\mathrm{m}$ & 3.8 \\
\hline Total number of containers inside magazine & 252 \\
\hline Total power produced in magazine, $\mathrm{W}$ & 1968 \\
\hline Ventilation stack height, $\mathrm{m}$ & 5.5 \\
\hline Ventilation stack diameter, $\mathrm{m}$ & 0.35 \\
\hline Container diameter, $\mathrm{m}$ & 0.5 \\
\hline Container length, $\mathrm{m}$ & 0.7 \\
\hline Distance between containers, $\mathrm{m}$ & 0.025 \\
\hline Ambient temperature, ${ }^{\circ} \mathrm{C}$ & 23 \\
\hline
\end{tabular}

The objective of this analysis is to develop a methodology for calculating surface temperatures for the containers. These temperatures can then be used in an analysis of heat transfer within the containers (not included in this work) for calculating pit temperatures. A full-scale discretization of the magazine is difficult due to the very complicated geometry of the stack of containers, the complexity of the flow, and the physical limitations of today's computers. The difficulty of the problem makes it necessary to use alternative methods for analysis. The work reported here shows an analysis in which results from three codes are combined to obtain a reasonably accurate result that does not require a full discretization. The codes are:

1. A commercial fluid mechanics code (FIDAP [4]) is applied to calculate the natural convection heat transfer coefficients on the containers.

2. A Fortran code, written specifically for this project, solves for the thermal radiation resistance existing between every pair of containers, and between every container and the wall, roof and floor.

3. A commercial lumped-parameter heat transfer code (SINDA [5]), which uses the convective and radiative data generated by the previous programs, solves for the surface temperature of each container.

Two problems are analyzed: an actual pit storage magazine and a tent. The tent is a simplified pit storage configuration evaluated in a recent experiment in LLNL [1]. The tent experiment includes a run (Test Run 5 [1]), in which four columns of storage containers with internal heat generation were instrumented (Figure 2) and monitored in a steady-state environment. This configuration is analyzed in this work because of its similarity with the magazine problem and also because it provides experimental data for validation of the model.

Use of the three codes is very much simpler than discretizing the whole domain. However, the magazine problem is still complicated due to the presence of 252 containers per magazine. To simplify the problem, only four columns of containers are analyzed, in a configuration identical to Test Run 5 for the tent (Figure 2). This simplification is done because this group of containers is expected to reasonably represent a segment of the whole array of containers, and using the same geometry as for the tent allows a direct comparison between the results. 
The following sections describe the application of each of the three codes to the problem being analyzed. The main assumptions used in the analysis are described along the way.

\section{Fluid Mechanics Analysis}

The purpose of the fluid mechanics analysis is to calculate natural convection heat transfer coefficients that can then be used in the lumped parameter analysis for calculating pit temperatures. The analysis is done with FIDAP, a commercial finite element fluid mechanics code [4]. The following assumptions are used in the analysis:

1. A two-dimensional model of the cylindrical containers is used, and the heat transfer coefficient calculated from the two-dimensional model is then assumed to apply to the whole cylinder (including the flat ends of the cylinders, not taken into account in the two-dimensional analysis). This is a reasonable assumption because the two flat ends of the cylinder represent only $27 \%$ of the total external cylinder area, and because conditions in the flat ends are similar to the conditions between the cylinders (natural convection in the presence of a plume of hot air generated by the lower cylinders).

2. Only two vertical columns of five containers each are considered in the analysis. Symmetry boundary conditions are used on both sides to reduce the computational effort. The results indicate that boundary layers are very thin and stay mainly within a single column of containers.

3. In the model of the two columns of containers the central third of the floor and ceiling are assumed to be open to the environment, and air flows through these openings due to buoyancy. This is a 2-D approximation of the actual 3-D condition in which air is drawn from the magazine into the container array due to buoyancy. This simplified model is used because the actual 3-D condition is probably too complicated to be simulated.

4. The turbulence wall model used by the fluid mechanics code requires a minimum size for the element closest to the wall, so that the Reynolds number defined in terms of the friction velocity and the thickness of the wall element is at least 30 (see [4], Theory Manual). This requirement limits the minimum distance between containers that can be used in the finite element mesh. While the actual distance between containers is 0.025 $\mathrm{m}$, the minimum distance for which a satisfactory mesh could be obtained is $0.1 \mathrm{~m}$ vertical distance between containers and $0.08 \mathrm{~m}$ horizontal distance. To estimate the error resulting from using the bigger distances, additional runs were made for three distances between containers.

Boundary conditions are: adiabatic roof and floor, and uniform heat flux on the cylindrical container surfaces. The value of the heat flux is $8 \mathrm{~W} / \mathrm{m}^{2}$, which closely corresponds to $12 \mathrm{~W}$ per container, considering that the container area is approximately equal to $1.5 \mathrm{~m}^{2}$. A heat flux of $12 \mathrm{~W} / \mathrm{m}^{2}$ is also used in the calculation to evaluate the effect of higher heat flux on heat transfer coefficient.

The grid is automatically generated by the code (Figure 3a). A converged solution is generally obtained after 1500 iterations with a segregated solver. Figures $3 \mathrm{~b}$ and $3 \mathrm{c}$ illustrate typical temperature and velocity fields around the containers. 
Convection heat transfer coefficients are found to be a strong function of position around the cylindrical container, but use of a lumped model to calculate temperatures requires only the use of average heat transfer coefficients. The FIDAP code automatically determines average convection coefficients. These average values are listed in Table 2 for five runs with different spacings and heat generation rates. Run 1 is for $0.08 \mathrm{~m}$ horizontal and $0.1 \mathrm{~m}$ vertical distance between containers, and $12 \mathrm{~W}$ of heat generation per container. These parameters are closest to the actual geometry and heat generation rates existing in the tent and magazine problems, so the coefficients from Run 1 are used in the lumpedparameter temperature calculations. Four other runs are shown to indicate the effect of distance between containers and heat generation on the calculated convection coefficients.

Table 2 shows that convection heat transfer coefficients increase slowly with increasing heat generation rate and increasing distance between containers. Because the true distance between containers is less than the minimum spacing we achieved using FIDAP, the actual convection coefficients are expected to be less than the values in Table 2. The maximum difference between the five runs is about $20 \%$. This small difference helps to quantify the magnitude of error introduced by using a spacing between containers that is bigger than the actual spacing. In the lumped-parameter analysis, an even greater excursion on the convection coefficient was performed by dropping all the values $50 \%$. Temperature changes resulting from this study were found to be small and are discussed in the results section of this report.

To confirm the range of convection heat transfer coefficients, and in order to validate the turbulence wall model in FIDAP, a textbook calculation for natural convection around a cylinder was done.

Using a correlation from Ref. [6], properties of air at $23{ }^{\circ} \mathrm{C}$, a container diameter of 0.5 meters, and assuming a temperature difference of $6{ }^{\circ} \mathrm{C}$ between the container surface and surrounding air, a Rayleigh number of $7.8 \times 10^{7}$ and an average convection coefficient of $2.7 \mathrm{~W} / \mathrm{m}^{2} \mathrm{~K}$ were calculated.

Table 2. Parameter study results from FIDAP.

\begin{tabular}{|l|c|c|c|c|c|}
\hline & Run 1 & Run 2 & Run 3 & Run 4 & Run 5 \\
\hline Distance between containers, m & & & & & \\
\hline Horizontal & 0.08 & 0.1 & 0.1 & 0.2 & 0.08 \\
\hline Vertical & 0.1 & 0.1 & 0.2 & 0.2 & 0.1 \\
\hline Power generation, W per container & 12 & 12 & 12 & 12 & 18 \\
\hline $\begin{array}{l}\text { Heat transfer coefficients for each layer } \\
\text { of containers, W/m }{ }^{2} \mathrm{~K}\end{array}$ & & & & & \\
\hline 5 (top layer) & 1.14 & 1.21 & 1.23 & 1.30 & 1.24 \\
\hline 4 & 1.15 & 1.29 & 1.36 & 1.37 & 1.26 \\
\hline 3 & 1.34 & 1.51 & 1.54 & 1.56 & 1.46 \\
\hline 2 & 1.55 & 1.75 & 1.80 & 1.82 & 1.69 \\
\hline 1 (bottom layer) & 2.62 & 2.99 & 3.13 & 3.22 & 2.91 \\
\hline
\end{tabular}

\section{Thermal Radiation Analysis}

Thermal radiation resistances are provided as data to the lumped-parameter code. A Fortran program was written and applied to the calculation of radiation resistances. The 
calculations are based on the methods and equations presented in [7]. The sequence of calculations followed by the program is:

1. Calculation of view factors. View factors between the cylindrical faces of the containers are calculated with the crossed-string method, assuming a two-dimensional geometry, due to the small distance between cylinders compared to the length. The flat ends of the containers do not radiate to other containers in the same stack. The view factors from the flat ends of the containers to the wall and to the opposite stack of containers (for the magazine problem) are calculated with view factor equations, assuming that the container ends are small (differential) compared with the other areas in the room. Once the view factors for the cylindrical surfaces and for the flat ends of the containers are known, the view factors for each whole container are calculated by using view factor algebra. View factors for the roof, walls and floor are calculated by using the appropriate equations.

2. Setting up the radiosity matrices. Emissivities and view factors are used to write the radiosity matrices, which relate heat flux to the fourth power of temperature.

3. Solving the radiosity matrices. This requires the application of a subroutine for matrix inversion, and a second subroutine for multiplying two matrices.

4. Generation of data file. The program finally generates a data file that can be directly included into the lumped parameter model. The data file contains $23 * 22 / 2=253$ radiation resistances for the current problem with 23 surfaces (20 containers, floor, walls, and roof).

Some view factors for the magazine problem are different from those used in the tent problem. The differences exist because of the different boundary conditions around the matrix of cylinders. The tent only contains four columns of containers. The magazine holds many more columns of containers, and the four columns being analyzed are only a small segment of the whole array. For the tent, the cylindrical faces of the containers in the end columns (labeled A and D in Figure 2) radiate to the tent walls, roof and floor. For the magazine, columns A and D radiate to other columns of containers, all hot due to internal heat generation. To simplify the magazine problem, containers in the end columns are assumed to be next to a symmetry mirror, and therefore radiate to themselves rather than radiating to the next row of containers. This assumption produced accurate results, because temperature gradients between columns are small.

The tent experimental setup (Figure 2) uses black storage containers (AL-R8), and stainless steel containers (AT-400A). It is assumed for this calculation that the black containers have an emissivity of 0.96 , and the stainless steel containers an emissivity of 0.85 , based on property data tables [7]. 


\section{Lumped-Parameter Model}

A lumped-parameter model uses an electrical circuit analogy to model the response of a thermally interacting system. The commercial lumped-parameter code SINDA [5] was used in calculating the pit storage container temperatures. The code has a graphical user interface, which makes it easy to set up the model by locating the nodes on the screen. The values of heat generation in each container can be changed for analyzing different cases. Values of convection or radiation resistances are changed by generating data files with the fluid mechanics or radiation codes. These files are then included into the lumped parameter model.

Figure 4 is a schematic of the two network models being analyzed. The figure indicates with solid lines the thermal resistance network for the magazine. For the tent, two additional radiation resistances are included, as indicated by the dotted lines. In both network models, each container is connected by radiation with the other 19 containers. These connections are not shown in the figure for clarity. Connections to the matrix of containers in the figure indicate that every individual container is connected to the opposite end of the resistance. The analysis assumes steady-state conditions.

The magazine and the tent resistance network models are very similar. They both assume that all containers exchange heat by convection to the ambient air which is at the temperature of the outdoor air. This is consistent with the definition of heat transfer coefficient used by FIDAP, which is based on the inlet air temperature. Only the roof is assumed to exchange heat by convection with the hot air that flows out through the stack.

The tent for the experiments was set up inside a building, and therefore the walls and roof of the tent radiate to the building walls. It is assumed that the walls of the building are at the same temperature as the ambient air. Radiation between the tent and the building is represented in Figure 4 by the radiation resistances between the building temperature and the walls and roof. In the magazine, the walls and roof are thick and are assumed to be adiabatic so these resistances are not included in the magazine lumped-parameter model.

Determination of the temperature of the hot air flowing up the stack requires a calculation of the air flow rate through the magazine. This calculation cannot be done with any of the three programs used thus far, so a separate analysis was done. This involved estimating the mass flow rate through the stack as a balance between the buoyancy forces, that tend to increase the air velocity; the pressure drops in the stack and in the intake registers, which tend to reduce the air velocity; and the kinetic energy of the air flowing out through the stack. The procedure is iterative. An air flow rate is initially assumed and then modified until converging to a solution. The resulting mass flow rate through the magazine is $0.17 \mathrm{~kg} / \mathrm{s}$ which corresponds to an average speed of $1.5 \mathrm{~m} / \mathrm{s}$. While this air flow rate is reasonable for the idealized model treated here, it may be very sensitive to external environmental variables, such as wind speed and direction and it will also depend on heat load within the magazine. We recommend a direct measurement of the air flow rate through the stack to validate this model and improve the accuracy of the magazine results.

\section{Results}

The methodology consisting of the codes described above is used to evaluate both the tent and the magazine. Three additional cases for the tent model are analyzed for evaluating the effect of convection and radiation on container temperatures. The five cases are described as follows: 
1. Case 1. This is the tent model, which simulates the container arrangement shown in Figure 2 (Run 5 in the experimental evaluation, [1]). The value of Max Watts in Figure 2 is assumed to be $15 \mathrm{~W}$ since this is the maximum value listed in the experimental setup.

2. Case 2. This is the magazine model applied to the same configuration of containers and heat generation rates as Case 1 .

3. Case 3. This is the same as Case 1, except that the convective heat transfer coefficients have been reduced by $50 \%$.

4. Case 4. This is the same as Case 1, except that all the containers inside the tent are assumed to be black, with an emissivity of 1.0.

5. Case 5. This is the same as Case 1, except that there is no radiation heat transfer.

The results are shown in Figures 5 and 6 and Table 3. Figure 5 shows the container temperatures for the parameter study of the tent model (Cases 1, 3 and 5), along with the experimental data. Figure 6 compares the results for the tent and magazine models (Cases 1 and 2). The results of Case 4 are not included in the figures because they fall within $0.1{ }^{\circ} \mathrm{C}$ of those for Case 1. This indicates that the containers can be analyzed as black bodies, greatly simplifying the radiative exchange problem without introducing significant errors. In Figures 5 and 6 , the following numbering scheme is used: element 1 is container $A-1$ in Figure 2; element 2 is B-1; and so on until reaching element 20 which is D-5.

Table 3 shows temperatures of the three remaining components (floor, walls, and roof) and temperatures used as boundary conditions in SINDA (ambient air, exhaust air, and building).

Table 3. Calculated temperatures of surrounding components and boundary conditions from SINDA.

\begin{tabular}{|l|c|c|c|c|c|}
\hline & Case 1 & Case 2 & Case 3 & Case 4 & Case 5 \\
\cline { 2 - 6 } Component & Tent Model & $\begin{array}{c}\text { Magazine } \\
\text { Model }\end{array}$ & $\begin{array}{c}\text { Reduced } \\
\text { Convection }\end{array}$ & $\begin{array}{c}\text { Black } \\
\text { Body }\end{array}$ & $\begin{array}{c}\text { No } \\
\text { Radiation }\end{array}$ \\
\hline $\mathrm{T}_{\text {floor }}$ & 24.1 & 25.8 & 24.5 & 24.1 & 22.9 \\
\hline $\mathrm{T}_{\text {walls }}$ & 23.3 & 25.6 & 23.5 & 23.3 & 22.9 \\
\hline $\mathrm{T}_{\text {roof }}$ & 24.4 & 28.7 & 24.3 & 24.4 & 28.1 \\
\hline $\mathrm{T}_{\text {amb air }}(\mathrm{BC})$ & 22.9 & 22.9 & 22.9 & 22.9 & 22.9 \\
\hline $\mathrm{T}_{\text {exhaust air }}(\mathrm{BC})$ & 33.2 & 33.2 & 33.2 & 33.2 & 33.2 \\
\hline $\mathrm{T}_{\text {building }}(\mathrm{BC})$ & 22.9 & $\mathrm{n} / \mathrm{a}$ & 22.9 & 22.9 & 22.9 \\
\hline
\end{tabular}

The experimental data consists of thermocouple temperatures measured at different locations around the surface of the container. For a given container, the temperature spread is about $2{ }^{\circ} \mathrm{C}$. Locations labeled "side," "mid side," and "lower side" in Figure 5 indicate measurements done in the cylindrical faces of the containers. Temperatures labeled as "top" and "bottom" are measured in the flat ends of the containers, and therefore are colder than the temperatures in the sides. The method of analysis applied to this problem uses a single 
lump for each container, and therefore it did not resolve a separate temperature for the side and end.

Figure 5 shows that the tent model predicts the experimentally measured temperatures within the range of experimental data spread. The calculated results for Case 1 fall between the experimental results for the sides and for the ends of the containers, and they closely approach the results for the sides. This result is expected, since the sides consist of over $70 \%$ of the total container area, and are therefore more representative of the average container temperature. Calculated temperatures for a few containers (elements 2, 3, 5, and 6) do not fall between the measured temperatures for the sides and for the ends. This may be because the power Max Watts used in the experiment is probably different than the value used in this analysis.

The results shown in Figure 5 for Case 3, with convection heat transfer coefficients reduced by $50 \%$, are about $1{ }^{\circ} \mathrm{C}$ higher than most measured temperatures, indicating the sensitivity of the model to the heat transfer coefficients. The results for Case 5 (with no radiative exchange) are substantially higher $\left(4\right.$ to $\left.6^{\circ} \mathrm{C}\right)$ than the experimental values, indicating the great importance of including radiation heat transfer in this problem. The results of Case 4 show that assuming black body radiation rather than the more difficult diffuse-gray model is sufficient to model the radiation.

Figure 6 compares the calculated results for the magazine with the tent. Results for the magazine show higher temperatures for all the containers, especially for the upper layers of containers, which exchange heat by radiation with the roof, which is kept warm by the air stream flowing out through the stack. As expected, the results for the magazine are sensitive to the temperature of the outlet air.

\section{Conclusions}

This report shows a modeling procedure for analysis of a pit storage magazine. The procedure is also applied to a tent that was used for a simplified experimental evaluation of the magazine. The procedure uses three codes. The first code calculates convective heat transfer coefficients, the second calculates radiation resistances and the third is a lumped parameter model that uses the convective and radiative resistances to calculate container wall temperatures. The main conclusions are as follows:

1. There is agreement between the calculated results for the tent and the experimental data. Therefore the computational procedure meets its purpose of predicting container surface temperatures.

2. The analysis of the tent problem indicates that including radiation heat transfer is very important in obtaining accurate results. The containers can be considered as black bodies, simplifying the radiation problem. Sensitivity of the results to the convective heat transfer coefficients was evaluated.

3. The model has also been applied to predicting container temperatures within an entire Pantex magazine. As expected, these are higher than the temperatures in the tent, but they have not been compared with Pantex data. The results are expected to be sensitive to the temperature of the air flowing out through the magazine stack.

\section{Acknowledgments}


The method of combining the codes for calculating container temperatures was originally conceived by Arthur Shapiro and Charles Landram. We also thank them, along with James Maltby and Richard Martin, for valuable discussions held during the progress of this project. We are grateful to Lucy Dobson for graphical artwork and skillful typing during the course of this project.

This work was funded by the Computational Mechanics Thrust Area of Mechanical Engineering, Gerald Goudreau, Thrust Area Leader. 


\section{References}

1. Fuhrman, P.W., Simulated Pantex Staging and Storage Thermal Tests, Lawrence Livermore National Laboratory Engineering Test Plan CODTU-95-0605, Test No. 2987, Livermore, CA, August 1995.

2. Buntain, G., Matsumoto, K., Steinke, R., Squires, J., Fuhrman, P., Lowrey, M., Rabie, R., Gregory, W., Bailey, R., Vidlak, T., Foster, P., and Duncan, A., PitStorage Monitoring, Los Alamos National Laboratory Report LA-12907, Los Alamos, NM, April 1995.

3. Gregory, W., Thermal and Airflow Analysis of Pantex 21A Stage Right Configured Modified Richmond Magazine, Los Alamos National Laboratory Report TSA8-LA-19, Los Alamos, NM, March 1995.

4. Fluid Dynamics International, Inc., FIDAP User's Manual Set Fluid Dynamics Package Reference Documentation Version 7.52, Evanston, Illinois, 1993.

5. Cullmore and Ring Technologies, SINDA/FLUINT User's Manual, Littleton, CO, September 1995.

6. Incropera, F. and DeWitt, D., Fundamentals of Heat Transfer, John Wiley \& Sons, New York, NY, 1981, page 447.

7. Siegel, R. and Howell, J., Thermal Radiation Heat Transfer, McGraw-Hill, Inc., New York, NY, 1972. 


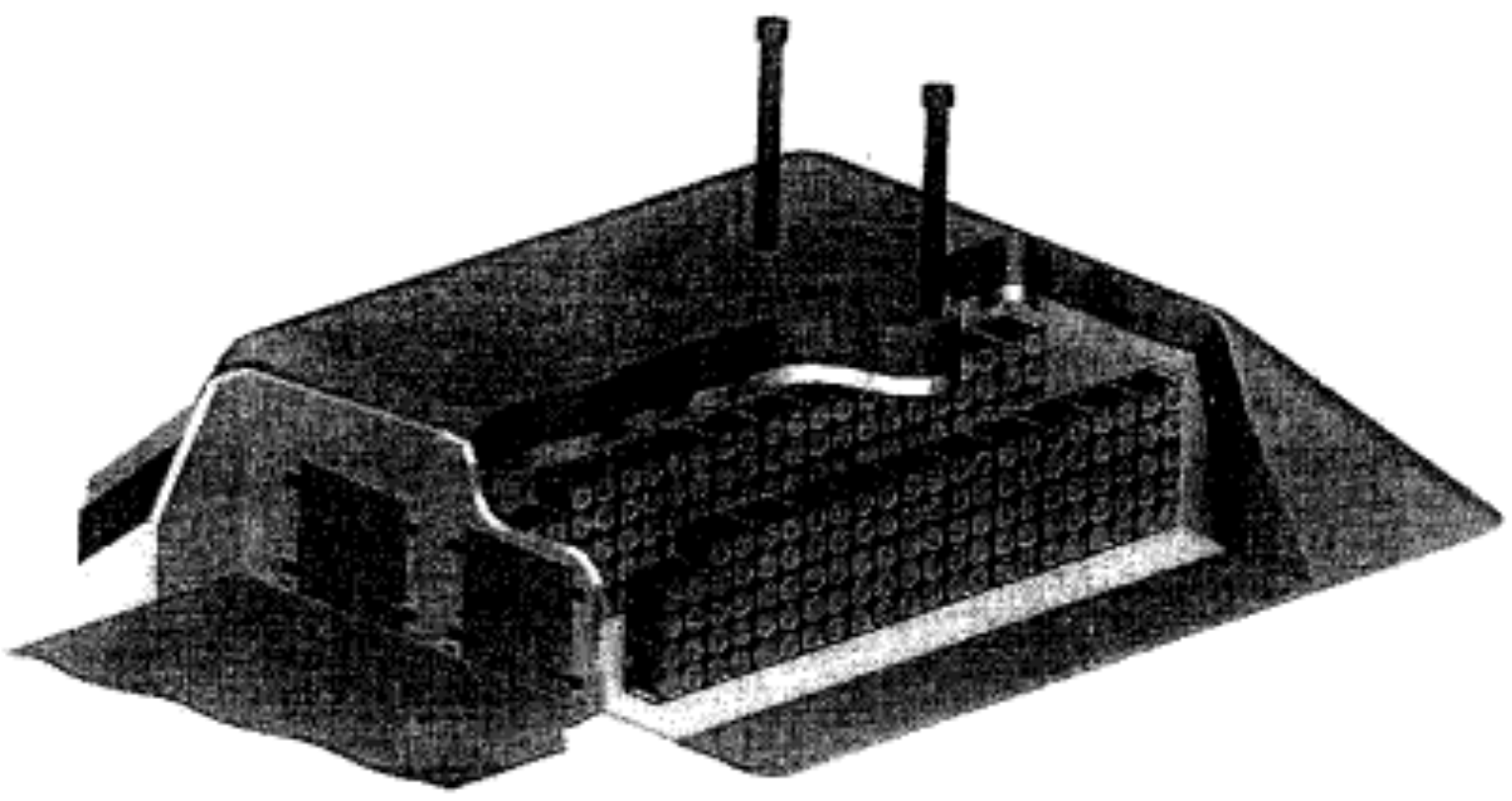

Figure 1. Artist's rendering of Pantex magazine and pit storage container arrangement (taken from Ref. [2]). 


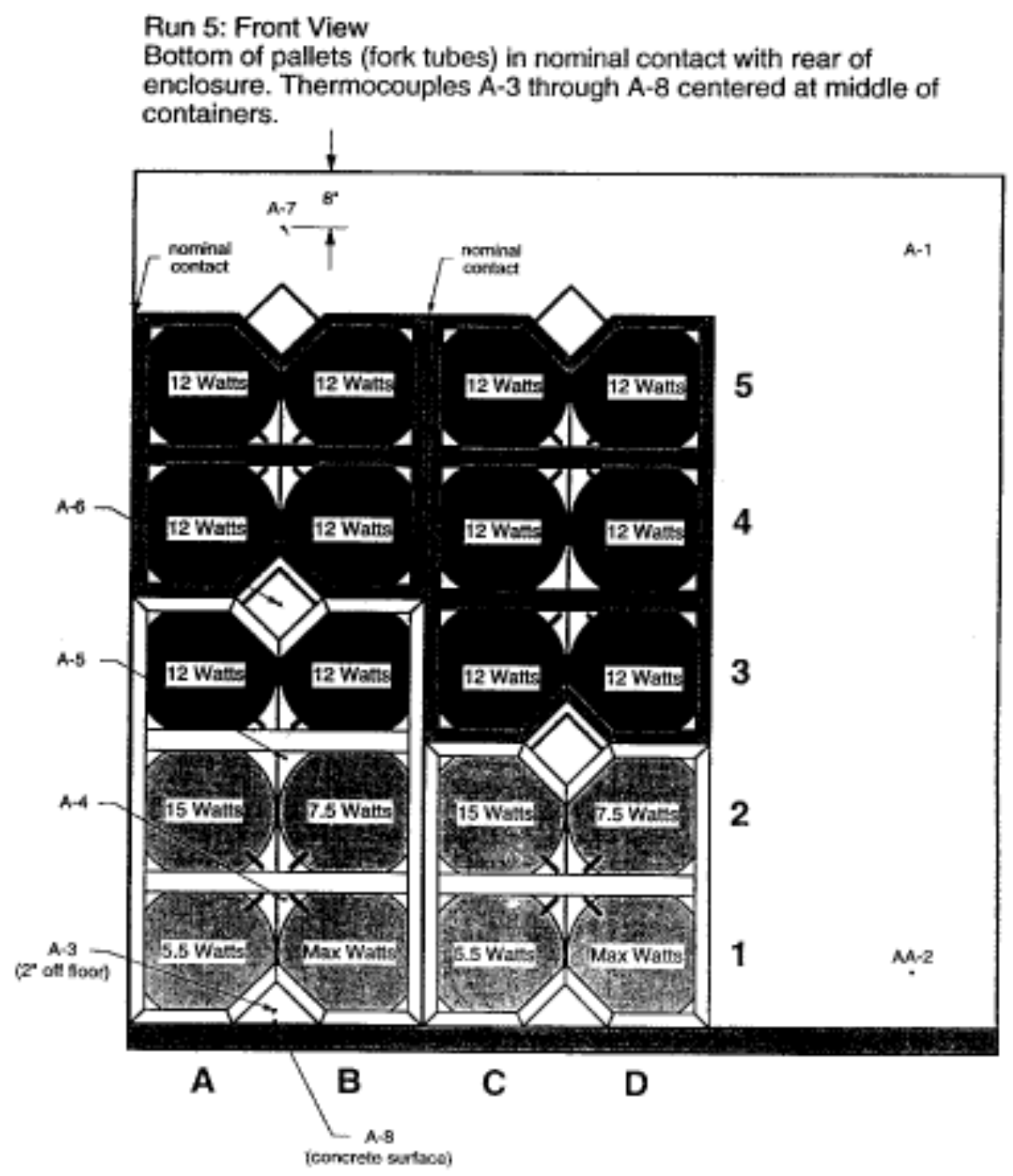

Figure 2. Schematic of tent experiment

(Test Run 5 from Ref. [1]). 


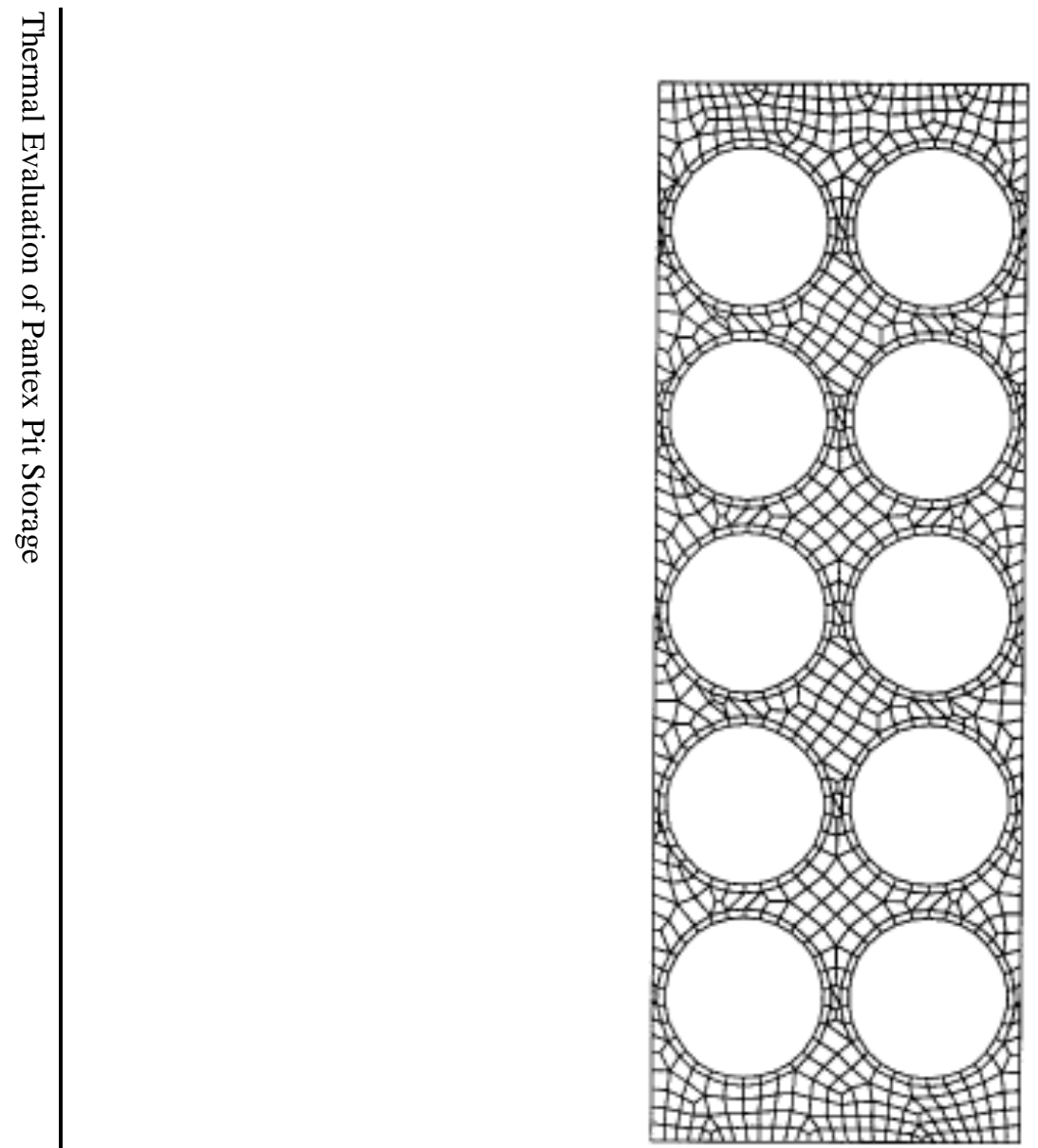

(a)

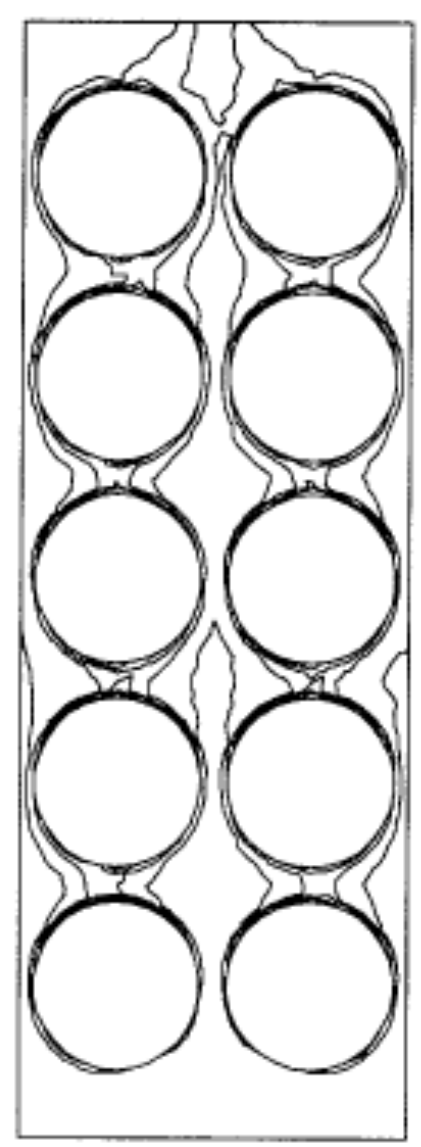

(b)

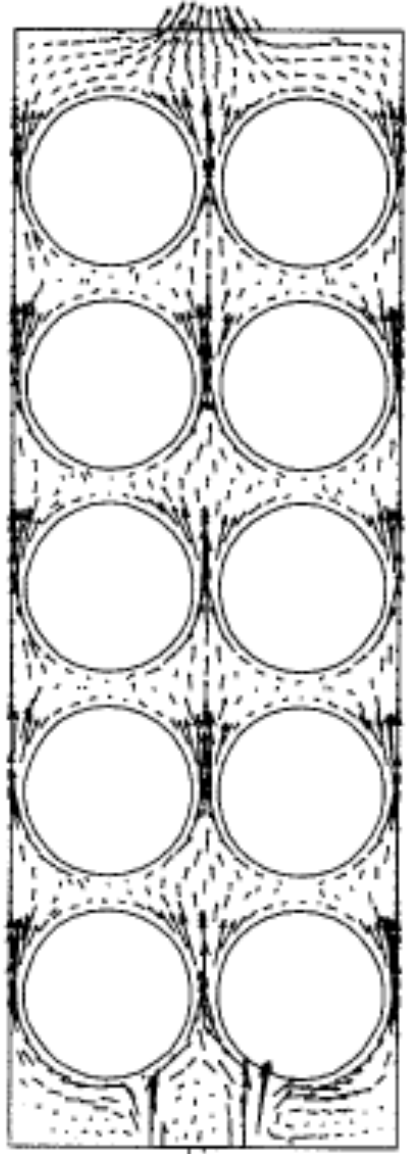

(c)

Figure 3. Typical FIDAP results: (a) finite element mesh, (b) temperature contours at $2^{\circ} \mathrm{C}$ intervals, (c) velocity vectors with range 0.05 to $0.47 \mathrm{~m} / \mathrm{s}$. 

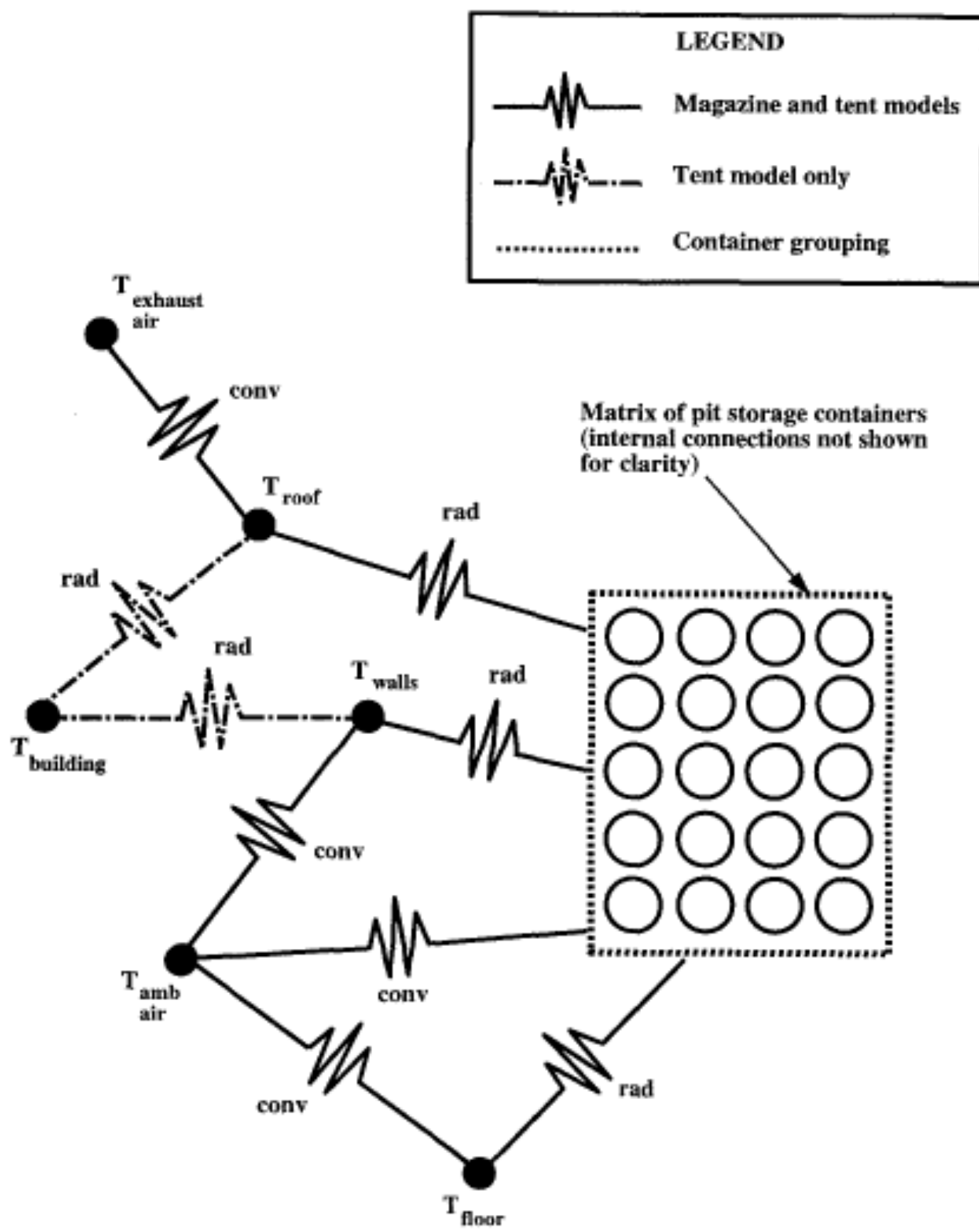

Figure 4. Schematic of lumped parameter model 


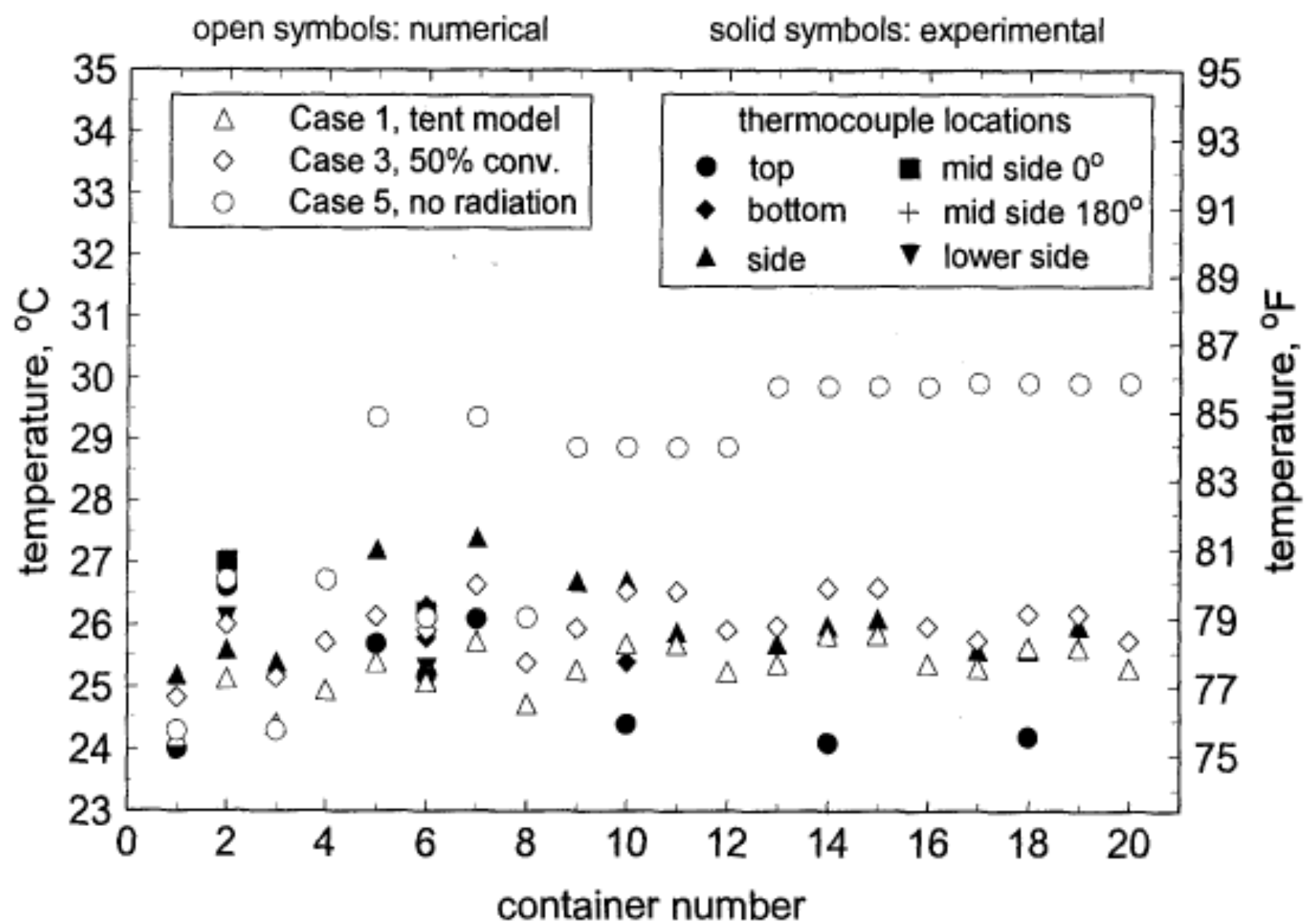

Figure 5. Parameter study of tent model and comparison with experimental data. 


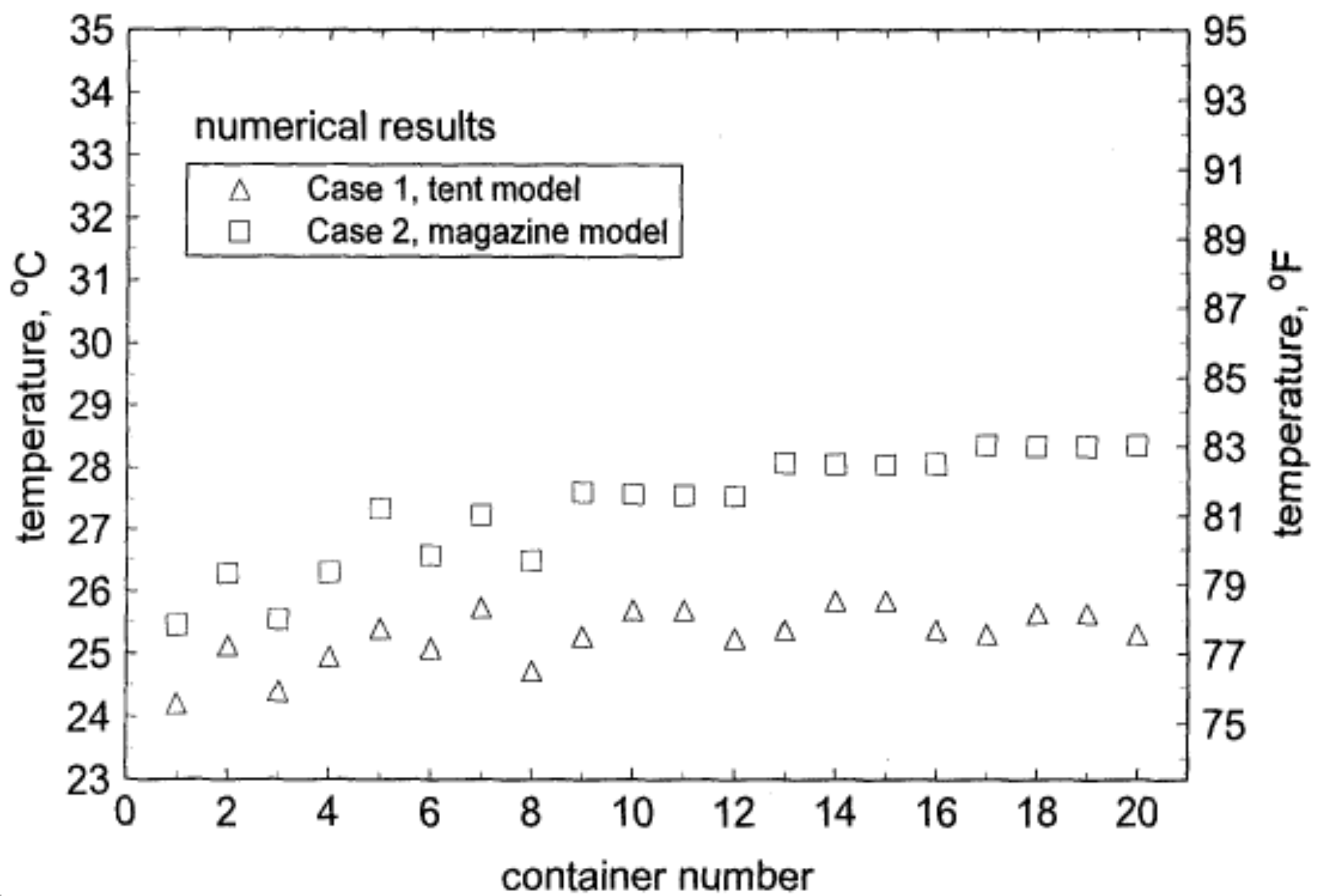

Figure 6. Comparison of tent and magazine model results. 


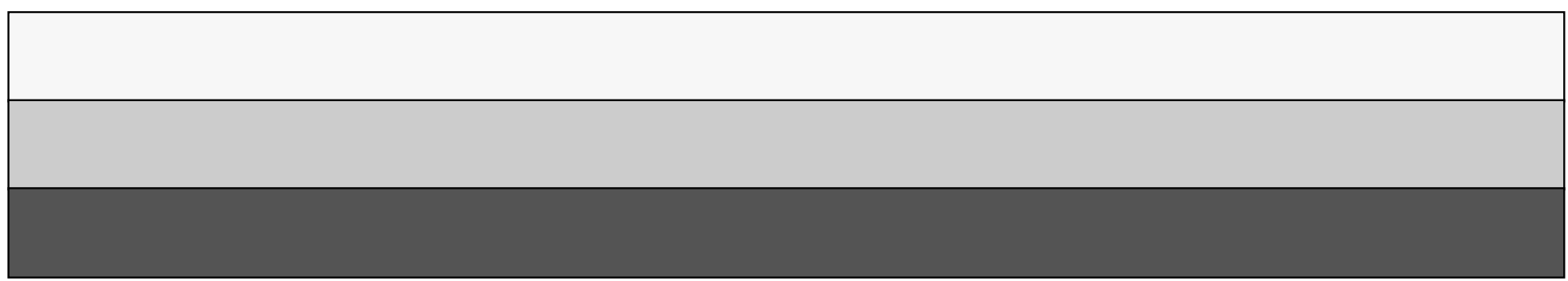

